\title{
COMPETITION AND
}

\section{Cost Overruns in Procurement*}

\author{
JUAN-JOSÉ GANUZA ${ }^{\dagger}$
}

October 2003

\begin{abstract}
Most cases of cost overruns in public procurement are related to important changes in the initial project design. This paper deals with the problem of design specification in public procurement and provides a rationale for design misspecification. We propose a model in which the sponsor decides how much to invest in design specification and awards competitively the project to a contractor. After the project has been awarded the sponsor engages in bilateral renegotiation with the contractor, in order to accommodate changes in the initial project's design that new information makes desirable. When procurement takes place in the presence of horizontally differentiated contractors, the design's specification level is seen to affect the resulting degree of competition. The paper highlights this interaction between market competition and design specification and shows that the sponsor's optimal strategy, when facing an imperfectly competitive market supply, is to underinvest in design specification so as to make significant cost overruns likely. Since no such misspecification occurs in a perfectly competitive market, cost overruns are seen to arise as a consequence of lack of competition in the procurement market.

KEYWORDS: Cost overruns, procurement contracts, strategic ignorance.
\end{abstract}

JEL classification numbers: L51, H57, D44.

\footnotetext{
${ }^{*}$ I gratefully acknolwledge financial support from the Spanish Ministry of Science and Technology under DGES grant BEC 2000-1026 and Ramón y Cajal grant. I specially would like to acknowledge Lambros Pechlivanos with whom I started to think about this project. His comments and discussions were crucial in the initial development of this paper. I wish to thank Kyle Bagwell, Antonio Cabrales, Aleix Calveras, Marco Celentani, Maria-Angeles de-Frutos, Jorge Duran, Belen Jerez, José Penalva, Steven Tadelis and participants at the ESEM 99 and LACEA 99 conferences for useful discussions and suggestions. The usual disclaimer applies. This paper is based on an earlier draft entitled "Competition and Cost Overruns. Optimal Misspecification of Procurement Contracts".

${ }^{\dagger}$ Department of Economics and Business, Universitat Pompeu Fabra, Carrer Ramón Trías Fargas, 23-27, 08005, Barcelona, Spain; fax: +34-93-542 1746; juanjo.ganuza@econ.upf.es.
} 


\section{INTRODUCTION}

Horror stories about public works or military procurement projects frequently appear in the press. Most of the cases that catch the attention of the public eye are characterized by long delays and huge cost overruns, usually associated with changes of the initial design of the projects. ${ }^{1}$ Accusations against the procuring agencies are focused on the issue of poor initial design. Agencies are portrayed as incompetent, or in some cases as corrupt, for not paying enough attention to the specification of projects before procuring them, thus resulting in renegotiation with the contractor over the projects.

This paper proposes a rationale behind this observed pattern. We show that it may be in the interest of the procurer to underinvest in design specification. The intuition behind this result is that, by reducing the design specification, the sponsor reduces the comparative advantage of the most efficient firm in the awarding process. By making firms more homogeneous the sponsor intensifies competition and this results in a lower transfer. We also show that the more competitive the market, the better specified the initial design will be. In particular, in a perfectly competitive market, in which firms earn no rents, no design misspecification takes place.

The main goal of the paper is to use the analysis of the specification design problem to study the cost overruns in public works. We find that cost overruns are decreasing in the design specification level. Then, using the relationship between competitiveness and incentives to design specification, we show that when the procurement market is more competitive cost overruns are lower. For this reason, cost overruns are argued to be a consequence of the lack of competition in the procurement market.

We study a simple procurement problem in which a sponsor wants to undertake a single

\footnotetext{
${ }^{1}$ The Boston harbor tunnel in Boston, USA, and the new subway system in Athens, Greece, are two archetypical examples of public projects plagued with such problems. Another example provided by Bajari and Tadelis (2001) is the construction of the Getty Center Art Museum in Los Angeles. The project design had to be changed due to unanticipated site conditions and regulatory requirements, and the construction of the project took over 8 years. While in public works cost overruns are important, cost overruns are endemic on defense procurement. For example, Peck and Scherer (1962) stimated that, for U.S defense programs, development cost exceds originals predictions by $220 \%$ on average. Chen and Smith (2001) cite Augustine (1986) to point out that in defense projects there is only a $10 \%$ change of meeting cost goals and a $15 \%$ chance of meeting schedule goals.
} 
project. There exists a fixed number of horizontally differentiated potential contractors. Prior to the awarding process, the sponsor decides how much to invest in specifying the design (or the blueprint) and this decision becomes public information. As a result of this learning process an initial design is specified. The sponsor awards the construction of the initial design using a competitive mechanism. Once the project is awarded to a contractor and in the course of its realization, new information about the optimal design is generated, and the awarded contractor and the sponsor engage in a bilateral renegotiation to change the initial design to accommodate the new information. Cost overruns, i.e., the difference between the final price and the price announced once the project is initially awarded, are a consequence of this renegotiation. As often claimed, a low investment in the initial design specification is likely to lead to negotiating significant changes and therefore to high cost overruns. ${ }^{2}$

Potential contractors in the procurement market are horizontally specialized in a specific design. As a consequence of this, the higher the investment in design specification, the higher the advantage of the contractor located closest to the initial design, and the larger its rents. From a different point of view, however, the higher the investment in initial design specification, the higher the probability that the awarded contractor will be the most efficient one, in the sense that the probability that the awarded contractor will be the closest to the final project design is higher. For this reason, when the sponsor decides how much to invest in design specification, he has to trade off optimally the reduction of procurement rents with the increase of the probability of choosing the most efficient firm.

To summarize, the present paper shows that it may well be that some misspecification of the initial design of the project is beneficial to the sponsor since leads to a more competitive environment. This is not to say that cost overruns are always strategic, as in fact we acknowledge that most cost overruns are because of unforeseen contingencies that were either missed because negligence or because were really impossible to predict, but to highlight that there are some

\footnotetext{
${ }^{2}$ Ganuza (1997), an empirical study of cost overruns in public works in Spain, tries to identify the magnitude and causes of cost overruns in larger public works. The largest 256 public work projects undertaken by the Spanish Administration during two years led to cost overruns $77 \%$ of the cases, average cost overruns were $22 \%$ of budgeted costs and $62,7 \%$ of cost overruns cases were related to changes in the projects' design during construction.
} 
benefits associated to misspecification and most importantly, that it is reasonable to expect that sponsor's incentives to invest in specifying the contract increase with market competition.

This article is related to two different branches of the literature. First, the paper relates to the literature concerning to explain the cost overruns and contract renegotiation in procurement. Our motivation is closer to Bajari and Tadelis (2001). They study a similar problem in which a buyer wishes to procure a product from a seller. As in the present paper, the buyer incurs a cost of specifying a initial design for the product. The design is incomplete, since when production begins, new information can make desirable to change the initial design of the product. The larger is the investment in specifying the product, the lower is the likelihood that both parties will need to change the design. They show that cost plus contracts are better than fixed price contracts when the project is more complex. We consider only fixed price contracts and a single type of project, but we add to the analysis the effect of firms competition over sponsor incentives in specifying the initial design of the product.

Lewis (1986) and Arvan and Leite (1989) study a framework in which: (a) procurement occurs over an extended period, (b) the sponsor and the contractor cannot credibly commit themselves to a long-term contract, (c) the contractor has better information about the cost of completing the project, and (d) most benefits accrue to the sponsor only after the project is completed. In this framework cost overruns occur because the opportunity cost of giving up the project increases. The price of each task depends on the credible threat of stopping the project. This threat is less credible for the later tasks that for the earlier ones. Thus the price that the sponsor pays increases over time, even when the expected cost of the all stages is the same. In the present model there is only one construction stage and, hence, we do not have this dynamic effect. Gaspar and Leite (1989) present a model in which the procurement mechanism induces an ex post downward bias on project cost and consequently cost overruns. In their model, the sponsor has to choose between $n$ potential contractors after receiving a signal about the real cost of the project for each contractor. This signal is the sum of the idiosyncratic cost of the firm and a measurement error. The firm with the lowest signal is the firm with the lowest expected cost. In addition, the expected measurement 
error for this firm is negative, leading to underestimation of the true cost, and cost overruns. We are not considering this sort of cost uncertainty, and, hence, do not study this effect in our model.

Our paper is also related to the literature that analyzes endogenous information structures in auctions, in particular with the papers focus on the incentives of sponsor to disclose information to bidders. The central result in this literature is the "linkage principle" derived by Milgron and Weber (1982) in an affiliated environment. This results states that to commit to fully and publicly announce all information the auctioneer has is the expected-revenue-maximizing policy. Recently, Bergemann and Pesendorfer (2003) and Ganuza (2003) show that this result can not be extended to private value environments. There is a fundamental difference between private and common value setting, when the principal disclose information to bidders previously to the auction. In common value environments, bidders react symmetrically to the information revealed by the auctioneer. In contrast, in a private value environment, when the principal disclose information of the object will raise the valuation of some bidders and reduce the valuations of others. An implication of this fact, is that the auctioneer has incentive to provide less information than would be efficient since by doing so, bidders become more homogenous and competition is increased. The present paper obtains a similar result in a procurement setting in which firms are horizontally differentiated. However, our analysis differs of the auctions models in two dimensions: (i) not only firms but the sponsor, have uncertainty about the optimal design of the project, and (ii) after the procurement auction we introduce an additional stage in which the sponsor and the winning firm can renegotiate the initial contract.

The remainder of the paper is organized as follows. In Section 2 the model is introduced while section 3 characterizes the efficient solution. Section 4 solves the model and presents the main results of the paper. In Section 5 we briefly consider the case in which the firms cannot observe the design specification level. Section 6 discusses the scope and implications of the model and presents conclusions. All proofs are all relegated to a technical appendix. 


\section{THE MODEL}

Consider a sponsor that plans to undertake a project. The payoff to the sponsor depends on the project's design $d \in D$, where the design space $D$ is a circle of perimeter one. Let $d^{*} \in D$ denote the optimal design for the sponsor and assume that the payoff to the sponsor from a project $d \in D$ is $V(d)=V-\left(d-d^{*}\right)^{2}$, where $V$ is a given real number, so that the payoff is decreasing in the distance between $d$ and $d^{*}$. The sponsor is initially uncertain about the exact location of the optimal design so that ex ante, $d^{*}$ is distributed according to the uniform distribution on the design space.

There are $N$ risk-neutral potential contractors $i=\{1, \ldots, N\}$. The location of each potential contractor $d_{i}$ is uniformly distributed on the circle $D$. Each potential contractor specializes in one design, its location $d_{i} \in D$, and its cost of completing an arbitrary design $d$ is $C_{i}(d)=C+\beta\left(d-d_{i}\right)^{2}$, where $\beta$ is meant to capture the specialization level in the contractors' market.

We assume that the sponsor has to make two decisions related to the project design. In a specification stage, before contracting, the sponsor conducts research on the location of $d^{*}$, and specifies an initial design, denoted by $\widehat{d}$ by choosing a specification investment $\delta \in[0, \infty)$; the way in which the stochastic relationship between $\widehat{d}$ and $d^{*}$ depends on $\delta$ is detailed below. Given $\widehat{d}$, the sponsor awards the project competitively to a potential contractor. During the realization of the project, new information about the optimal design arises and the sponsor may renegotiate the initial contract $\widehat{d}$ with the awarded contractor.

The initial design is partially correlated with the optimal design, in particular we assume it is a noisy signal of the optimal design, $\widehat{d}=d^{*}+\varepsilon$, where the noise $\varepsilon$ is distributed over $\left[-\frac{1}{2}, \frac{1}{2}\right]$ according with the distribution function $G(\varepsilon \mid \delta)$. We make the following assumptions about this distribution:

Assumption 1 The density function associated to $G(\varepsilon \mid \delta)$ is symmetric and centered at 0 .

Assumption 2 When $\delta=0, G(\varepsilon \mid \delta)$ is equal to the uniform distribution on $\left[-\frac{1}{2}, \frac{1}{2}\right]$. When 
$\delta \rightarrow \infty$, the $G(\varepsilon \mid \delta)$ converges to ${ }^{3}:$

$$
G(\varepsilon \mid \infty)= \begin{cases}0 & \text { if } \varepsilon<0 \\ 1 & \text { otherwise }\end{cases}
$$

Assumption $3 G(\varepsilon \mid \delta)$ is differentiable and decreasing in $\delta$ for all $\varepsilon$ lower than $0, \frac{\partial G(\varepsilon \mid \delta)}{\partial \delta}<0$ for all $\varepsilon \in\left(-\frac{1}{2}, 0\right)$, and $G(\varepsilon \mid \delta)$ is differentiable and increasing in $\delta$ for all $\varepsilon$ greater than $0, \frac{\partial G(\varepsilon \mid \delta)}{\partial \delta}>0$ for all $\varepsilon \in\left(0, \frac{1}{2}\right) .^{4}$

[Figure 1 around here]

Given these assumptions $\widehat{d}$ is also distributed uniformly around the circle, and by assumption 1 it is an unbiased estimator of the optimal design. Assumption 2 implies that when $\delta=0$ the initial design is not correlated with the optimal design, whereas when $\delta=\infty$ the initial design coincides with the optimal design. Assumption 3 implies that the variance of the noise decreases with $\delta .5$ Therefore, the greater the specification investment (the larger $\delta$ ), the closer is in expected terms the initial design of the optimal one.

After the initial design has been specified and the specification level has become public information, the awarding process takes place. Notice that once the bidders observe $\widehat{d}$, the distribution of $d^{*}$ is no longer uniform. $d^{*}$ is then distributed on the circle according to a posterior distribu-

\footnotetext{
${ }^{3}$ That is, as $\delta$ goes to infinity, the probability that $\varepsilon$ will be equal to zero converges to 1 .

${ }^{4}$ The truncated normal distribution defined on the interval $\left[-\frac{1}{2}, \frac{1}{2}\right]$, when the underliying normal distribution has mean $\mu=0$ and variance $\sigma=\frac{1}{\delta}$, is an example of distribution that is consistent with these three assumptions.

$$
G(\varepsilon \mid \delta)=\frac{\int_{-\frac{1}{2}}^{\varepsilon} \exp \left\{-s^{2} \delta\right\} d s}{\int_{-\frac{1}{2}}^{\frac{1}{2}} \exp \left\{-s^{2} \delta\right\} d s} .
$$

${ }^{5}$ An alternative assumption to Assumption 3 might be:

Assumption $\mathbf{3}^{\prime}$ If $\delta>\delta^{\prime}$, we can order the distribution functions $G(\varepsilon \mid \delta)$ and $G\left(\varepsilon \mid \delta^{\prime}\right)$ in the sense of first order stochastic dominance: $G(\varepsilon \mid \delta) \leq G\left(\varepsilon \mid \delta^{\prime}\right) \forall \varepsilon \in\left[-\frac{1}{2}, 0\right], G(\varepsilon \mid \delta) \geq G\left(\varepsilon \mid \delta^{\prime}\right) \forall \varepsilon \in\left[0, \frac{1}{2}\right]$.

An example of a distribution that is consistent with this new assumption is the uniform distribution on an interval decreasing in $\delta,\left[-\frac{1}{2(1+\delta)}, \frac{1}{2(1+\delta)}\right]$ :

$$
G(\varepsilon \mid \delta)=\left\{\begin{array}{lll}
0 & \text { if } & \varepsilon<-\frac{1}{2(1+\delta)} \\
(1+\delta) \varepsilon+\frac{1}{2} & \text { if } & \varepsilon \in\left[-\frac{1}{2(1+\delta)}, \frac{1}{2(1+\delta)}\right] \\
1 & \text { if } & \varepsilon>\frac{1}{2(1+\delta)}
\end{array}\right.
$$

Under this alternative assumption, using the techniques of Milgrom and Shanon (1994), we would obtain the same monotone comparative results. However, Assumption 3 allows us to obtain strictly monotonic results.
} 
tion $F(d \mid \delta)$ depending on the initial $\widehat{d}$ and the specification level $\delta .{ }^{6}$ Firms using $F(d \mid \delta)$ update their believes over the optimal design and submit their offers to the sponsor. All firms know the locations of their competitors and this information is verifiable by the sponsor. ${ }^{7}$ The sponsor awards the public work to the most convenient firm (taking into account its bid and its location technology). The winning firm signs a contract to undertake the initial design. ${ }^{8}$ During the construction of the project, the sponsor and the firm learn the optimal design, and change the initial contract using bilateral renegotiation that is represented by a Nash Bargaining procedure.

The sponsor's preferences over final outcomes are represented by the following utility function $U_{S}=V(d)-p-\delta$, where $V(d)$ is valuation of the project and $p$ is the project's price. We want to characterize the sponsor's optimal investment in design specification, taking into account how this investment is going to affect the result of the auction process (the winning firm and the procurement price) as well as the contract's renegotiation. Summarizing, the time sequence of the model is as follows:

1. The sponsor, knowing the number of firms in the market, $N$, decides his expenditures on research, $\delta$, and specifies an initial design $\widehat{d}$ for the project. The specification level $\delta$ becomes public information.

\footnotetext{
${ }^{6}$ For notational convenience, we take the location of $\widehat{d}$ as the origin of the circle, and we define $F(d \mid \delta)$ on the interval $\left[\widehat{d}-\frac{1}{2}, \widehat{d}+\frac{1}{2}\right]$. Given the above assumptions over the noise distribution, $F(d \mid \delta)$ presents the following characteristics: (i) The density function associated to $F(d \mid \delta)$ is symmetric and centered at $\widehat{d}$. (ii) When $\delta=0$, $F(d \mid \delta)$ is equal to the uniform distribution on $\left[\widehat{d}-\frac{1}{2}, \widehat{d}+\frac{1}{2}\right]$. When $\delta \rightarrow \infty, F(d \mid \delta)$ converges to the Dirac delta function on $\widehat{d}$ (iii) $F(d \mid \delta)$ is decreasing in $\delta$ for all $d$ lower than $\widehat{d}$ and increasing in $\delta$ for all $d$ greater than $\widehat{d}$.

${ }^{7}$ Therefore, firms compete in the procurement process like in standard Bertrand competition among heterogenous firms. The purpose of looking at such simplified setting is to avoid unnecessary complications in the presentation. We can show that introducing the assumption of asymmetric information over the firm's location does not change the results of the model as long as we do not consider contracts over realizations of $d^{*}$. If $d^{*}$ is contractible we can commit to inefficient ex-post renegotiations of the optimal design in order to reduce the informational rents (See for example Che (1993)). We are assuming that $d^{*}$ is not contractible and therefore we are not exploring this problem. However, our conjecture, is that the main results of the paper would still remain when $d^{*}$ is contractible. Commiting to inefficient renegotiation of the contract and misspecifying the initial design are two ways to reduce firm rents, and we expect the sponsor would use both of them, if he could.

${ }^{8}$ Notice that procuring $\widehat{d}$ is an optimal strategy for the sponsor. He can not increase his profits by procuring another design since he does not know ex-ante the location of the firms and the firms are located according to a uniform distribution. In a related paper Ganuza and Pechivanos (2000) study a model in which the location of the firms and the optimal design are public knowledge (and there is no design renegotiation). In this model the optimal strategy for the sponsor is to procure a design different from the optimal one (between the optimal design and the location of the most disadvantaged firm), since by doing that he increases firm competition in the procurement process.
} 
2. The sponsor announces the initial design. Firms learn their location (with respect to $\widehat{d}$ ) and present their bids to the sponsor. The sponsor awards the public project to the firm that maximizes his expected utility considering its bids and its location technology.

3. The winning firm and the sponsor learn the optimal design $d^{*}$ and, through a Nash bargaining procedure, decide the final design and the final price to be paid for the project. ${ }^{9}$

In the next section we study the benchmark case by characterizing the efficient solution. Section 4 provides the solution of the model.

\section{EFFiCIENT SOLUTION}

In this section, we consider the problem of a social planner, who chooses the design specification level $\delta^{E}$, the winning firm $d_{w}$, and the final design $d^{E}$ that maximize total surplus (the sum of sponsor's utility and the profits of the winning firm), $W=E\left\{U_{S}+\pi_{w}\right\}=E\left\{V(d)-C_{w}(d)-\delta\right\}$. In maximizing total surplus the planner faces the same informational constraints as the sponsor so that the timing of the efficient procurement process can be described as follows:

1. Given the number of firms in the market, $N$, the social planner decides research expenditure $\delta$ and specifies an initial design $\widehat{d}$ for the project.

2. Given $\widehat{d}$, the social planner learns the location of the firms and chooses the winning firm.

3. In the course of the construction of the project, the social planner learns the optimal design.

Given the location of the winning firm and the optimal design, the social planner chooses a final design for the project.

We solve the model using backwards induction. The next subsection characterizes the final design given the winning firm and the optimal design. Subsection 3.2 will then select the optimal firm to undertake the project given the initial design, the locations of the firms and the design

\footnotetext{
${ }^{9}$ This model tries to capture the institutional framework which is used by public administrations to procure large public works. See Jofre-Bonet and Pesendorfer (2003) and Bajari and Tadelis (2001) for a overview of the building construction industry.
} 
specification level. Lastly, subsection 3.3 studies the sponsor problem and provides the efficient design specification level.

\subsection{Final design}

In the construction stage, when the social planner learns the optimal design $d^{*}$, he chooses the final design of the project given this optimal design and the location of the winning firm $d_{w}$. Let $d^{E}$ be the optimal final design which maximizes the total surplus of the project.

$$
d^{E} \in \underset{d}{\operatorname{argmax}} V(d)-C_{w}(d)
$$

Thus the optimal final design is

$$
d^{E}=\frac{\beta d_{w}+d^{*}}{1+\beta}
$$

The optimal final design turns out to be an average between the location of the awarded firm and the optimal project design. The weight of the firm's location in the average depends on the technological parameter $\beta$. In particular, the larger the specialization of the market (the larger $\beta$ ) the closer is the final design to the location of the awarded firm. Notice that when $\beta=0$, the case of homogenous firms, the cost does not depend on the design and the final design is the optimal one. On the contrary, when $\beta=\infty$, firms can only produce one design, and the final design is trivially the location of the winning firm.

\subsection{The most efficient firm}

In the awarding process the social planner has to choose a firm after learning all firms' locations, $d_{w}, i \in\{1, \ldots, N\}$. Given $d^{E}$, the expected surplus of the project depends on the location of the winning firm and on the specification level of the initial design. Let $S\left(d_{i}, \delta\right)$ be the expected surplus of the project if it assigned to a firm with location $d_{i}$ when the design specification level is $\delta$

$$
S\left(d_{i}, \delta\right)=E_{d^{*}}\left\{V\left(d^{E}\right)-C_{i}\left(d^{E}\right) \mid \delta\right\} .
$$


The following lemma shows how the expected surplus of the project depends on the firm's location.

Lemma 1 If $\delta>0$, then the expected surplus is decreasing in the distance between the initial design and the location of the firm. If $\delta=0$, then the expected surplus does not depend on the distance between the initial design and the location of the firms.

Let $d_{1}$ be the closest location to the initial design $\widehat{d}$. Then an immediate corollary of the previous Lemma characterizes the firm that maximizes the expected surplus.

Corollary 1 The efficient winning firm is the closest firm to the initial design $d_{w}=d_{1}$.

The intuition behind this result is the following. The expected surplus of the project will depend on the distance between the winning firm and the optimal design. Since the initial design is an unbiased estimator of the optimal design, the closest firm to the initial design is (in expected terms) the closest firm to the optimal one. Hence, the closest firm is the most efficient firm exante. On the other hand, if the social planner does not invest in design specification, the optimal design can be with the same probability on any arbitrary place in the circle, implying that the expected surplus of any firm is the same. Notice that the firm with location $d_{1}$ may turn out to be not the most efficient firm ex-post and that the probability of this event is decreasing in the design specification. ${ }^{10}$

\subsection{Optimal design specification}

In the specification stage, the social planner has to choose the investment in design specification knowing the number of firms. The expected surplus of the project is now only a function of the design specification level.

$$
S(\delta)=E_{d_{1}}\left\{S\left(d_{1}, \delta\right)\right\}
$$

The next result characterizes the relationship between the expected surplus of the project and the specification level of the design.

\footnotetext{
${ }^{10}$ We do not consider the possibility of replacing the incumbent firm. As a matter of fact, the main results do not change when we introduce this possibility in the model, as long as the sponsor incurs in a positive cost to replace the incumbent firm.
} 
Lemma 2 The expected surplus of the project is increasing in the specification level of design, $\delta$.

Lemma ?? rests on the fact that the larger is the investment in the project design specification, the better is the matching between the technology of the winning firm and the sponsor's preferences.

Given the above, the social planner has to choose the investment in design specification trading off increases in the expected surplus of the project against the cost of specifying the initial project. The optimal specification design level is the solution to this problem

$$
\delta^{E} \in \underset{\delta}{\operatorname{argmax}} E_{d_{1}}\left\{S\left(d_{1}, \delta\right)-\delta\right\}
$$

First observe that given that $S\left(d_{1}, \delta\right)$ is bounded above, $\delta^{E}$ has to be finite. In the following we will assume that $\delta^{E}>0$, an assumption which is justified if the cost of providing very basic information about the optimal design is sufficiently small. Then, we have:

Proposition 1 The optimal design specification level $\delta^{E}$ is increasing in the number of firms $N$ and the technological parameter $\beta$.

The total procurement surplus depends on the distance between the location of the awarded firm and the optimal design. When the number of firms increases, the expected distance between the initial design and the awarded firm decreases, with the implication that the incentives to make this initial design closer to the optimal one also increase. Following a similar argument, if the technological parameter $\beta$ increases, the incentives to reduce the distance between the awarded firm and the optimal design also increases (the match between the sponsor's preferences and the contractor's technology becomes most important). The only way for the sponsor to ensure an appropriate match is to reduce the distance between the optimal design and the initial one and this in turn can only be accomplished by increasing the investment in design specification. ${ }^{11}$

\footnotetext{
${ }^{11}$ Notice that we did not impose assumptions on the convexity of the problem and therefore we cannot guarantee that the sponsor's problem is concave. We use the techniques of Edlin and Shannon (1998), that allow us to get comparative static results in non convex problems, as long as the cross derivatives' conditions are globally satisfied by the problem, a condition that is satisfied in our case.
} 


\section{Competitive Solution}

We solve the model using backwards induction. The next subsection characterizes the solution of the design's renegotiation. Subsection 4.2 provides the result of the competitive mechanism. Subsection 4.3 concludes the analysis of the model by studying what is the optimal design specification level.

\subsection{Renegotiation of the initial design}

When the awarded contractor and the sponsor learn the optimal design, they bargain over the final design $d^{C}$ and the final price of the project $p_{F}$. At this renegotiation stage they know the initial design $\widehat{d}$, the procurement price $p_{p}$, and the location of the winning firm $d_{w}$. We assume that the outcome of the bargaining process is the solution of a generalized Nash bargaining problem. ${ }^{12}$

Let $\pi_{S}\left(d^{C}, p_{F}\right)$ denote the agreement payoff to the sponsor when the final design is $d^{C}$ and the final price $p_{F}$ and $\rho_{S}\left(\widehat{d}, p_{p}\right)$ his disagreement point. Let $\pi_{F}\left(d^{C}, p_{F}\right)$ denote the agreement payoff to the winning firm and $\rho_{F}\left(\widehat{d}, p_{p}\right)$ its disagreement point. The final design $d^{C}$ and final price $p_{F}$ will then be given by the solution to the following problem:

$$
\max _{d^{C}, p_{F}}\left(\pi_{S}-\rho_{S}\right)^{1-\alpha}\left(\pi_{F}-\rho_{F}\right)^{\alpha}
$$

Where $\alpha$ is the firm's bargaining power. Payoff functions are defined as follows. The sponsor's final surplus is the utility of the final design minus the new price and the investment in design specification, $\pi_{S}\left(d^{C}, p_{F}\right)=V-\left(d^{C}-d^{*}\right)^{2}-p_{F}-\delta$ and his disagreement point is given by the utility of the initial design minus the procurement price and the investment in design specification, $\rho_{S}\left(\widehat{d}, p_{p}\right)=V-\left(\widehat{d}-d^{*}\right)^{2}-p_{p}-\delta$. The awarded firm's final profit is the new price minus the cost of the new design, $\pi_{F}\left(d^{C}, p_{F}\right)=p_{F}-C-\beta\left(d^{C}-d_{w}\right)^{2}$. Its disagreement point is the procurement price minus the cost of the initial design, $\rho_{F}\left(\widehat{d}, p_{p}\right)=p_{p}-C-\beta\left(\widehat{d}-d_{w}\right)^{2}$. Given these payoff

\footnotetext{
${ }^{12}$ Notice that in contrast with other models, the assumption of Nash bargaining is not important in our model, since the negotiation rents of the awarded contractor are discounted in the auction. Different bargaining procedures can be shown to lead to the same results.
} 
functions, the Nash bargaining problem can be rewritten as follows

$$
\max _{d^{C}, p_{F}}\left(-\left(d^{C}-d^{*}\right)^{2}-p_{F}+\left(\widehat{d}-d^{*}\right)^{2}+p_{p}\right)^{\alpha}\left(p_{F}-\beta\left(d^{C}-d_{w}\right)^{2}-p_{p}+\beta\left(\widehat{d}-d_{w}\right)^{2}\right)^{1-\alpha}
$$

and its solution is characterized in the next lemma.

Lemma 3 The bargaining solution for the final design and the final price is given by:

$$
\begin{aligned}
d^{C}= & \frac{\beta d_{w}+d^{*}}{1+\beta} \\
p_{F}= & p_{p}+\beta\left(d^{C}-d_{w}\right)^{2}-\beta\left(\widehat{d}-d_{w}\right)^{2} \\
& +\alpha\left(-\left(d^{C}-d^{*}\right)^{2}+\left(\widehat{d}-d^{*}\right)^{2}-\beta\left(d^{C}-d_{w}\right)^{2}+\beta\left(\widehat{d}-d_{w}\right)^{2}\right) .
\end{aligned}
$$

We are assuming that in this stage the sponsor and the firm both learn the optimal design. It is easy to check that as long as the sponsor knows the location of the awarded firm, this assumption is not necessary. Suppose that only the awarded firm learns the optimal design and it has to report it to the sponsor. The firm will report the design that maximizes its expected rents, but given the result of the renegotiation, the expected rents are $\alpha\left(\pi_{S}+\pi_{F}-\rho_{S}-\rho_{F}\right)$, and the design that maximizes these rents is the optimal design.

Since the bargaining procedure is efficient, we obtain the same final design as in the efficient solution $d^{C}=d^{E}$. The final price can be seen to be equal to the procurement price, plus the cost to change from the initial design to the final one, plus a proportion $\alpha$ (bargaining power) of the surplus generated by the bargaining process: $p_{F}=p_{p}+C_{w}\left(d^{C}\right)-C_{w}(\widehat{d})+\alpha\left(\pi_{S}+\pi_{F}-\rho_{S}-\rho_{F}\right)$.

\subsection{Price Competition}

Procurement proceeds in three steps. First, firms observe $\delta$ and $\widehat{d}$ and learn their location with respect to $\widehat{d}$. Second, each firm submits a bid, a location-price pair. Third, the sponsor, taking into account the location of the firms and the price, awards the project to the firm that submitted the bid that maximizes its expected utility $U_{S}$. The next proposition characterizes the solution at the procurement stage. 
Lemma 4 The closest firm wins the auction $d_{w}=d_{1}$, and the procurement price is

$$
p_{p}=C_{1}(\widehat{d})-E_{d^{*}}\left\{\alpha\left(\pi_{S}+\pi_{F}-\rho_{S}-\rho_{F}\right) \mid \delta\right\}+S\left(d_{1}, \delta\right)-S\left(d_{2}, \delta\right),
$$

where $d_{1}$ is the closest firm to the initial design and $d_{2}$ is the second closest firm.

The procurement price has three components: the cost of the initial project, the expected rents from future renegotiation (which are discounted), and the winning firm's expected profit $S\left(d_{1}, \delta\right)-S\left(d_{2}, \delta\right)$

Proposition 2 The expected profit of the winning firm is increasing in the specification level of the design $\delta$.

This is an important result for the paper: The higher is the specification level of the design, the higher is the market power of the winning firm, because the firm's location becomes more important. In other words, when the initial design is more accurate, the comparative advantage of the closest firm over the next closest increases and this leads to higher mark-up rents. The implication of this result is that the sponsor can use the specification level of the design to control firms' rents.

\subsection{Initial design optimal specification}

The sponsor has to find the specification of initial design that maximizes its expected surplus $\delta^{C}$, given the expectations on the procurement and renegotiation stages

$$
\delta^{C} \in \underset{\delta}{\operatorname{argmax}} E_{d_{1}, d_{2}, d^{*}} U_{S}=\underset{\delta}{\operatorname{argmax}} E_{d_{1}, d_{2}, d^{*}}\left\{V\left(d^{C}\right)-p_{F}-\delta\right\}
$$

Substituting the expression of the final price into the expected surplus we obtain

$$
U_{S}=E_{d_{1}, d_{2}, d^{*}}\left\{V\left(d^{C}\right)-p_{p}+C_{w}\left(d^{C}\right)-C_{w}(\widehat{d})+\alpha\left(\pi_{S}+\pi_{F}-\rho_{S}-\rho_{F}\right)\right\}-\delta .
$$

and substituting the expected procurement price into this expression and simplifying we obtain

$$
U_{S}=E_{d_{1}, d^{*}}\left\{V\left(d^{C}\right)-C_{1}\left(d^{C}\right)\right\}+E_{d_{1}, d_{2}}\left\{-S\left(d_{1}, \delta\right)+S\left(d_{2}, \delta\right)\right\}-\delta .
$$


Since $E_{d_{1}, d^{*}}\left\{V\left(d^{C}\right)-C_{1}\left(d^{C}\right)\right\}=E_{d_{1}}\left\{S\left(d_{1}, \delta\right)\right\}$, we finally obtain that

$$
U_{S}=E_{d_{2}}\left\{S\left(d_{2}, \delta\right)-\delta\right\}
$$

and the initial design optimal specification is the solution to

$$
\delta^{C} \in \underset{\delta}{\operatorname{argmax}} E_{d_{2}}\left\{S\left(d_{2}, \delta\right)-\delta\right\}
$$

Comparing this expression to ?? it is easy to see that the expected surplus of the sponsor does not depend on the location of the firm closest to the initial design, i.e., the winning firm (as is the case in the efficient solution) but depends on the location of the firm which is the second closest to the initial design. Apart from this fact, the problem is identical to the efficient one in ?? and the intuition of the results presented in the following Proposition is the same as in Proposition 1.

Proposition 3 The optimal design specification level $\delta^{C}$ in the competitive case is increasing in the number of the firms $N$ and the technological parameter $\beta$.

The following proposition presents the main result of the paper.

Proposition 4 The competitive specification level is less than the efficient design specification level, $\delta^{C}<\delta^{E}$. The difference between the efficient solution and the competitive solution converges to 0 as the number of firms goes to infinity

As was remarked above, the sponsor's problem would be equivalent to the social planner's problem if in the latter we considered the second closest firm instead of the closest firm. Using this fact, it is easy to see the intuition of the proposition. From Proposition 1 we know that the larger the number of firms, the closer the winning firm to the initial design, and the larger the incentives to specify the initial design. Using the same argument, if we take the second closest firm instead of the closest firm, there should be less incentives to specify the initial design.

This proposition shows an important trade-off in design specification. Assume that the starting point is the competitive solution. If the sponsor increases the level of specification the total surplus of the procurement process goes up. This is due to the fact that the final design is closer in expected 
terms to the optimal one and the winning firm is the most likely to be the most efficient firm to undertake the final design, ex-post. On the other hand, the increase in design specification also increases the rents of the winning firm, and this effect turns out to compensate the first one. Another way to see the intuition behind the result is that by reducing design specification, the comparative advantage of the closest firm in the awarding process decreases. In other words, the sponsor underinvests in the initial specification of the project to make potential contractors more homogeneous, with the underlying goal to intensify competition and reduce its expected transfer.

Finally, when the number of firms goes to infinity, the rent of the closest firm converges to 0 because the expected distance with the second closest firm also converges to 0 . In such case, the sponsor's trade off between reducing the firm rents and increasing the procurement surplus is eliminated as can be seen from the fact that $E_{d_{1}}\left\{S\left(d_{1}, \delta\right)\right\}-E_{d_{2}}\left\{S\left(d_{2}, \delta\right)\right\}$ goes to 0 .

\subsection{Cost overruns}

In the introduction we mentioned the relationship existing between design misspecification and cost overruns. This subsection is devoted to formalize this relationship. Usually cost overruns are defined as the difference between the procurement price and the final price:

$$
C_{C O}=p_{F}-p_{p}=C_{1}\left(d^{C}\right)-C_{1}(\widehat{d})+\alpha\left(\pi_{S}+\pi_{F}-\rho_{S}-\rho_{F}\right) .
$$

The next result derives the relationship between expected cost overruns and the initial design specification.

Proposition 5 Expected cost overruns of the project are decreasing in the design specification level, $\delta$

In other words, since cost overruns are due to reforms of the initial design, the better the initial design, the fewer reforms of the design will be needed and this implies lower expected cost overruns. An immediate Corollary characterizes the important relationship between competition and cost overruns. 
Corollary 2 Expected cost overruns of the project are decreasing in the number of the firms $N$.

In other words, the more competitive the procurement market, the lower expected cost overruns will be. This might be an important result since it shows that any policy devoted to promote competition in the procurement market, may have the positive effect of reducing cost overruns.

Proposition ?? and Corollary ?? have an empirical content, they predict that, ceterist paribus, more competitive markets lead to more accurate designs and lower cost overruns. In this line, anecdotal evidence suggest that cost overruns are especially important in military procurement which is a sector characterized by lack of competition. We look forward to future research devoted to formally test these results.

\section{IMPERFECT INFORMATION}

We are assuming that the information related to the optimal design is symmetric between the sponsor and contractors. In this section we briefly consider the case the sponsor has some private information about the real location of the optimal design. The way in which we model that is that the sponsor does not missrepresent the initial design $\widehat{d}$ (he does not have incentives to do that, given the symmetry of our setting) but firms cannot observe the level of design specification. The timing and structure of the game are the same as in the previous section.

1. The sponsor, knowing the number of firms in the market, $N$, decides his expenditures on research, $\delta$, and specifies an initial design $\widehat{d}$ for the project. The firms can not observe $\delta$ but they have a common expectation $\delta^{\prime}$ over it.

2. The sponsor announces the initial design. Firms learn their location (with respect to $\widehat{d}$ ) and given their expectations, present their bids to the sponsor. The sponsor awards the public project to the firm that maximizes his expected utility considering the firm's bid and its location technology.

3. The winning firm and the sponsor learn the optimal design $d^{*}$ and, through a Nash bargain- 
ing procedure, decide the final design and the final price to be paid for the project.

We solve the model using backwards induction.

\subsection{Renegotiation of the initial design}

The renegotiation process between the sponsor and the winning firm has the same solution that in the previous game (when the awarded contractor learns $d^{*}$ the specification level does not play any role). Therefore, given the optimal design $d^{*}$ and the winning firm $d_{w}$, the final design and the final price are the same than in the previous section

$$
\begin{aligned}
d^{I I}= & \frac{\beta d_{w}+d^{*}}{1+\beta} \\
p_{F}^{I I}= & p_{p}^{I I}+\beta\left(d^{I I}-d_{w}\right)^{2}-\beta\left(\widehat{d}-d_{w}\right)^{2} \\
& +\alpha\left(-\left(d^{I I}-d^{*}\right)^{2}+\left(\widehat{d}-d^{*}\right)^{2}-\beta\left(d^{I I}-d_{w}\right)^{2}+\beta\left(\widehat{d}-d_{w}\right)^{2}\right) .
\end{aligned}
$$

As a consequence, the focus is on the procurement stage and the design specification problem.

\subsection{Price competition}

The procurement proceeds as in the previous section. In order to solve the problem we have assumed that the firms have common expectation regarding the project's specification level $\delta^{\prime}$. Given this expectation, we obtain similar results to those in the previous section: the closest firm to the initial design wins the auction $d_{w}=d_{1}$, the procurement price will be

$$
p_{p}^{I I}=C_{1}(\widehat{d})-E_{d^{*}}\left\{\alpha\left(\pi_{S}+\pi_{F}-\rho_{S}-\rho_{F}\right) \mid \delta^{\prime}\right\}+S\left(d_{1}, \delta^{\prime}\right)-S\left(d_{2}, \delta^{\prime}\right) .
$$

\subsection{Initial design optimal specification}

Given the above, the sponsor's ex ante payoff is

$$
E_{d_{1}, d_{2}, d^{*}}\left\{U_{S}\right\}=E_{d_{1}, d_{2}, d^{*}}\left\{V\left(d^{I I}\right)-p_{F}^{I I}-\delta\right\} .
$$


and substituting the final price we get

$$
\begin{aligned}
E_{d_{1}, d_{2}, d^{*}}\left\{U_{S}\right\}= & E_{d_{1}, d_{2}, d^{*}}\left\{V\left(d^{I I}\right)-C_{1}\left(d^{I I}\right)-\alpha\left(\pi_{S}+\pi_{F}-\rho_{S}-\rho_{F}\right)\right\} \\
& +E_{d_{1}, d^{*}}\left\{\alpha\left(\pi_{S}+\pi_{F}-\rho_{S}-\rho_{F}\right) \mid \delta^{\prime}\right\}+E_{d_{1}, d_{2}}\left\{-S\left(d_{1}, \delta^{\prime}\right)+S\left(d_{2}, \delta^{\prime}\right)\right\}-\delta .
\end{aligned}
$$

Notice that, when unobserved, the specification level chosen by the sponsor cannot affect firms' expectation $\delta^{\prime}$ so that the term

$$
E_{d_{1}, d^{*}}\left\{\alpha\left(\pi_{S}+\pi_{F}-\rho_{S}-\rho_{F}\right) \mid \delta^{\prime}\right\}+E_{d_{1}, d_{2}}\left\{-S\left(d_{1}, \delta^{\prime}\right)+S\left(d_{2}, \delta^{\prime}\right)\right\}
$$

does not depend on $\delta$. Given this the sponsor's problem is equivalent to the following problem

$$
\delta^{I I} \in \underset{\delta}{\operatorname{argmax}} E_{d_{1}}\left\{S\left(d_{1}, \delta\right)\right\}-E_{d_{1}, d^{*}}\left\{\alpha\left(\pi_{S}+\pi_{F}-\rho_{S}-\rho_{F}\right)\right\}-\delta
$$

and we have the following result.

Proposition 6 If the winning firm has some bargaining power $\alpha>0$, the competitive specification level with imperfect information is higher than the efficient design specification level $\delta^{I I}>\delta^{E}$. If the sponsor has all the bargaining power $\alpha=0$, in the ex post renegotiation of the contract, then the solution is the efficient solution.

Observe that the sponsor knows that firms discounts design renegotiation rents in their bids but is unable to affect these discounts. For this reason, he tries to reduce firms' ex post rents by overinvesting in design specification. The higher the investment in design's specification, the lower the rents of the winning firm during the renegotiation process.

In order to calculate the sponsor's total surplus note that the sponsor has a dominant strategy $\delta^{I I}$ given that he can not affect firms' expectations. Although this is not important to derive the equilibrium design specification level (as $\delta^{I I}$ turns out to be a dominant strategy, given the continuation game) in a Nash equilibrium firms correctly forecast the sponsor's strategy, so that $\delta^{\prime}=\delta^{I I}$. Using this fact, the next corollary shows that the sponsor is worse off than in the case in which firms can observe the design specification level. 
Corollary 3 Under unobservability of design specification level, the Nash equilibrium payoff for the sponsor is

$$
U_{S}=E_{d_{2}}\left\{S\left(d_{2}, \delta^{I I}\right)-\delta^{I I}\right\}
$$

and is lower than the Nash equilibrium payoff of the case with observable design specification level

Corollary ?? provides a reasonable result. When comparing a Stackelberg game (the case in which firms can observe $\delta$ ) with the case in which firms cannot observe such $\delta$, the sponsor's profits are larger in the former case. An important implication of this corollary is that the sponsor has incentives to keep the information related to the optimal design symmetric (to provide to the firms all the information related to the optimal design, making the specification level $\delta$ observable). In the case of public procurement there are two ways in which the sponsor can make $\delta$ observable:

- The sponsor can commit to an observable design specification by delegating an independent firm the task of specifying the initial design.

- Given information on the value of $\delta$ can be inferred ex-post, a sponsor that cares about future payoffs may want to establish a reputation for underinvesting in the specification of the initial design to intensify competition among contractors.

\section{Conclusions}

Since public procurement accounts for a significant fraction of economic activity and since it is not unusual that public project end up with a final cost several times higher than the initial estimates, cost overruns are a very important issue for economists, politicians and the public.

The first goal of this paper was to provide an explanation for cost overruns in public procurement. We have developed a model in which cost overruns arise as a consequence of the renegotiation of an initial contract. Given existing uncertainty on the project's optimal design, the sponsor can devote resources to provide an initial estimate. Since this is costly, the sponsor is likely to provide a description of the project that, while an unbiased estimate of the optimal location will differ from it in all probability. Given this, as the project's optimal location is learned in 
the realization stage, the awarded contractor and the sponsor are likely to have strong incentives to engage in a bilateral renegotiation to modify the initial design of the project. Cost overruns arise as a consequence of this design renegotiation.

Our results show that in equilibrium the sponsor has incentives to invest less in the design's specification than would be efficient (keeping into account only the cost of the initial design specification). The intuition of the result is that by reducing design specification, the sponsor promotes fiercer competition among contractors: Lowering the initial design specification, homogenizes horizontally differentiated potential contractors and in particular decreases the comparative advantage of the most efficient firm.

This paper sheds light on one trade off in public procurement. While a more accurate specification of an initial design increases the probability to award the project to the most efficient firm, it also increases the rents of the latter. Since under perfect competition there no design misspecification takes place (as rents are eliminated) the above mentioned trade off disappears and the initial design specification is the efficient one. Given this cost overruns can be seem as a consequence of lack of competition in the procurement market and we can conclude that public policies promoting competition in procurement markets are also likely to reduce cost overruns in public works.

Finally, we have to point out that our analysis has been carried out under the assumption of symmetric information related to the optimal design between sponsor and potential contractors. In the working paper version of this paper Ganuza (2003), it is shown that this assumption is necessary for our results. However, it is also shown that this is a sensible assumption since the sponsor obtains higher profits by keeping symmetric the information related to the optimal design. The sponsor can commit to keep the information symmetric by establishing a reputation if he has a long term relationship with contractors or by delegating to an independent firm the task of specifying the initial design. 


\section{A APPENDix}

As a convention and without loss of generality we are going to consider in the appendix that $\widehat{d}=0$ and $d_{i}, d_{1}, d_{2} \in\left[0, \frac{1}{2}\right]$. We need to state some preliminary facts before we start with the proofs of the results.

Let $G_{d_{1}}(d, N)$ and $G_{d_{i}}(d, N)$ be the distributions of the expected distance between the initial design $\widehat{d}$ and the closest firm $d_{1}$ and the firm which is the firm $i$ closest to $\widehat{d}$, respectively. These distributions do not depend on the initial design and it can be shown that $\frac{\partial G_{d_{1}}(d, N)}{\partial N}<0$ $\forall d \in\left(0, \frac{1}{2}\right)$. These distributions are ordered in a strict first order stochastic dominance sense, $G_{d_{1}}(d, N)>G_{d_{i}}(d, N)$, for all $d \in\left(0, \frac{1}{2}\right)$.

Proof of lemma ??: The expected surplus of an arbitrary firm $d_{i}$ given that the initial design is $\widehat{d}=0$ and the specification level is $\delta$, is

$$
\begin{aligned}
S\left(d_{i}, \delta\right) & =E_{d^{*}}\left\{V\left(d^{E}\right)-C_{i}\left(d^{E}\right) \mid \delta\right\} \\
& =E_{d^{*}}\left\{V-C-\left(d^{E}-d^{*}\right)^{2}-\beta\left(d^{E}-d_{i}\right)^{2} \mid \delta\right\}
\end{aligned}
$$

By plugging $d^{E}=\frac{\beta d_{i}+d^{*}}{1+\beta}$ into the expression and then factorizing, we get

$$
S\left(d_{i}, \delta\right)=E_{d^{*}}\left\{V-C-\frac{\beta}{1+\beta}\left(d_{i}-d^{*}\right)^{2} \mid \delta\right\}
$$

Since $d^{*}$ is distributed on $\left[-\frac{1}{2}, \frac{1}{2}\right]$ according to $F(d \mid \delta)$, this expectation is

$$
S\left(d_{i}, \delta\right)=V-C-\int_{-\frac{1}{2}}^{\frac{1}{2}} \frac{\beta}{1+\beta} \min \left\{\left(d_{i}-s\right)^{2},\left(1-\left|d_{i}-s\right|\right)^{2}\right\} f(s \mid \delta) d s .
$$

Notice that, due to the fact that the design space is a circle, there are two distances between $d_{i}$ and $d^{*}$ and we have to consider only the shortest length arc.

$$
\begin{aligned}
S\left(d_{i}, \delta\right)= & V-C-\int_{0}^{\frac{1}{2}-d_{i}} \frac{\beta}{1+\beta}\left(d_{i}-s\right)^{2} f(s \mid \delta) d s-\int_{\frac{1}{2}-d_{i}}^{\frac{1}{2}} \frac{\beta}{1+\beta}\left(d_{i}-s\right)^{2} f(s \mid \delta) d s- \\
& -\int_{-\frac{1}{2}+d_{i}}^{0} \frac{\beta}{1+\beta}\left(d_{i}-s\right)^{2} f(s \mid \delta) d s-\int_{-\frac{1}{2}}^{-\frac{1}{2}+d_{i}} \frac{\beta}{1+\beta}\left(1-d_{i}+s\right)^{2} f(s \mid \delta) d s
\end{aligned}
$$


By using the symmetry of $F(d \mid \delta)$ we get

$$
\begin{aligned}
S\left(d_{i}, \delta\right)= & V-C-\int_{0}^{\frac{1}{2}-d_{i}} \frac{\beta}{1+\beta}\left(\left(d_{i}-s\right)^{2}+\left(d_{i}+s\right)^{2}\right) f(s \mid \delta) d s \\
& -\int_{\frac{1}{2}-d_{i}}^{\frac{1}{2}} \frac{\beta}{1+\beta}\left(\left(d_{i}-s\right)^{2}+\left(1-d_{i}-s\right)^{2}\right) f(s \mid \delta) d s \\
S\left(d_{i}, \delta\right)= & V-C-\int_{0}^{\frac{1}{2}} \frac{2 \beta}{1+\beta}\left(d_{i}{ }^{2}+s^{2}\right) f(s \mid \delta) d s-\int_{\frac{1}{2}-d_{i}}^{\frac{1}{2}} \frac{\beta}{1+\beta}\left(1-2\left(d_{i}+s\right)\right) f(s \mid \delta) d s .
\end{aligned}
$$

Integrating by parts the second term we get

$$
S\left(d_{i}, \delta\right)=V-C-\frac{\beta}{1+\beta}\left(d_{i}^{2}+\int_{0}^{\frac{1}{2}} 2 s^{2} f(s \mid \delta) d s-2 d_{i}+\int_{\frac{1}{2}-d_{i}}^{\frac{1}{2}} 2 F(s \mid \delta) d s\right) .
$$

It is interesting to see the special cases $\delta=0$ and $\delta=\infty$. We have that

$$
S\left(d_{i}, 0\right)=V-C-\frac{\beta}{1+\beta} \int_{0}^{\frac{1}{2}} 2 s^{2} d s
$$

If there is no investment in design specification, the expected surplus does not depend on the location of the firm. On the other hand

$$
S\left(d_{i}, \infty\right)=V-C-\frac{\beta}{1+\beta} d_{i}^{2}
$$

when the initial design is the optimal one, case $\delta=\infty$, the expected surplus only depends on the location of the firm. For interior cases, we differentiate $S\left(d_{i}, \delta\right)$ with respect to $d_{i}$

$$
\frac{\partial S\left(d_{i}, \delta\right)}{\partial d_{i}}=-\frac{\beta}{1+\beta}\left(2 d_{i}-2+2 F\left(\frac{1}{2}-d_{i} \mid \delta\right)\right)
$$

By using that $F\left(\frac{1}{2}-d_{i} \mid \delta\right)$ is increasing in $\delta$, and $\frac{\partial S\left(d_{i}, 0\right)}{\partial d_{i}}=0$, we can conclude that given the firm's location $d_{i}$, this expression is negative for $\delta>0$. Then the surplus is decreasing in the distance between the initial design and the firm's location.

Proof of lemma ??: The expected procurement surplus, given that the winning firm is the closest firm to the initial design, is

$$
S(\delta)=E_{d_{1}}\left\{S\left(d_{1}, \delta\right)\right\}=E_{d^{*}, d_{1}}\left\{V-C-\frac{\beta}{1+\beta}\left(d_{1}-d^{*}\right)^{2} \mid \delta\right\}
$$

Therefore, to prove the lemma we have to show that $E_{d^{*}, d_{1}}\left\{\left(d^{*}-d_{1}\right)^{2} \mid \delta\right\}$ is decreasing on $\delta$. First, we analyze the sum of the expected quadratic distance between the optimal design and all the 
firms. Let $A_{i}$ be the expected quadratic distance between the optimal design and the firms which is firm $i$ closest to the initial design.

$$
\begin{aligned}
\sum_{i=1}^{N} A_{i}= & E_{d^{*}, d_{1}}\left\{\left(d^{*}-d_{1}\right)^{2} \mid \delta\right\} \\
& +E_{d^{*}, d_{2}}\left\{\left(d^{*}-d_{2}\right)^{2} \mid \delta\right\}+\cdots+E_{d^{*}, d_{N}}\left\{\left(d^{*}-d_{N}\right)^{2} \mid \delta\right\}
\end{aligned}
$$

Rearranging terms we get

$$
\sum_{i=1}^{N} A_{i}=N A_{1}+\sum_{i=2}^{N} A_{i}-A_{1}
$$

It is clear that this sum does not depend on $\delta$ since the relative position of the firms is not important when we are adding all the distances. Therefore, the derivative of this sum respect to $\delta$ has to be 0 ,

$$
N \frac{\partial A_{1}}{\partial \delta}+\sum_{i=2}^{N} \frac{\partial\left(A_{i}-A_{1}\right)}{\partial \delta}=0
$$

The next step is to show that $\frac{\partial A_{i}-A_{1}}{\partial \delta}>0$ for every $i \neq 1$. Using similar computations to those in the proof of Lemma ?? we get ${ }^{13}$

$$
A_{i}-A_{1}=\int_{0}^{\frac{1}{2}}\left(z^{2}-2 z+\int_{\frac{1}{2}-z}^{\frac{1}{2}} 2 F(s \mid \delta) d s\right)\left(g_{d_{i}}(z, N)-g_{d_{1}}(z, N)\right) d z .
$$

Integrating by parts

$$
\begin{aligned}
A_{i}-A_{1}= & {\left[\left(z^{2}-2 z+\int_{\frac{1}{2}-z}^{\frac{1}{2}} 2 F(s \mid \delta) d s\right)\left(G_{d_{i}}(z, N)-G_{d_{1}}(z, N)\right)\right]_{0}^{\frac{1}{2}}+} \\
& -\int_{0}^{\frac{1}{2}}\left(2 z-2+2 F\left(\frac{1}{2}-z \mid \delta\right)\right)\left(G_{d_{i}}(z, N)-G_{d_{1}}(z, N)\right) d z .
\end{aligned}
$$

Finally, taking the derivatives respect to $\delta$

$$
\frac{\partial A_{i}-A_{1}}{\partial \delta}=-\int_{0}^{\frac{1}{2}} 2 \frac{\partial F\left(\frac{1}{2}-z \mid \delta\right)}{\partial \delta}\left(G_{d_{i}}(z, N)-G_{d_{1}}(z, N)\right) d z>0 .
$$

Since $\frac{\partial F(s \mid \delta)}{\partial \delta}>0$ and $G_{d_{1}}(z, N)>G_{d_{i}}(z, N) \forall z \in\left(0, \frac{1}{2}\right)$. But given that the derivative of the sum is 0 , and given that $\frac{\partial\left(A_{i}-A_{1}\right)}{\partial \delta}>0$ for every $i \neq 1$, this implies that $\frac{\partial A_{1}}{\partial \delta}<0$, which concludes the proof.

Proof of proposition ??: We are going to use a result of Edlin and Shannon (1998), that allows us to obtain strictly monotonic static comparative results without making assumptions on the concavity of the distribution functions.

\footnotetext{
${ }^{13}$ Notice, that $d_{X}$ and $d^{o}$ are independent variables, and we do not need to specify the joint distribution.
} 
Theorem 1 (Edlin and Shannon (1998)) Let $S \subset \Re, f: \Re \times \Re \rightarrow \Re, x^{*} \in \operatorname{argmax}_{x \in S} f\left(x, t^{*}\right)$ and $x^{\prime} \in \operatorname{argmax}_{x \in S} f\left(x, t^{\prime}\right)$. Suppose that $f$ is $C^{1}$ and has increasing marginal returns, and that $x^{*} \in$ int $S$. Then $x^{\prime}>x^{*}$ if $t^{\prime}>t^{*}$, and $x^{\prime}<x^{*}$ if $t^{\prime}<t^{*}$.

We have to check that we can apply this theorem to our decision problem. Our problem is:

$$
\begin{aligned}
\max _{\delta} E_{d_{1}}\left\{S\left(d_{1}, \delta\right)-\delta\right\} & \\
=\int_{0}^{\frac{1}{2}}\left(V-C-\frac{\beta}{1+\beta}\left(z^{2}+\int_{0}^{\frac{1}{2}} 2 s^{2} f(s \mid \delta) d s-2 z+\int_{\frac{1}{2}-z}^{\frac{1}{2}} 2 F(s \mid \delta) d s\right)\right) & \times g_{d_{1}}(z, N) d z-\delta .
\end{aligned}
$$

We define the objective function $f(x, t)$ as

$$
\begin{aligned}
f(\delta, N)=\int_{0}^{\frac{1}{2}}\left(V-C-\frac{\beta}{1+\beta}\left(z^{2}+\int_{0}^{\frac{1}{2}} 2 s^{2} f(s \mid \delta) d s-2 z+\int_{\frac{1}{2}-z}^{\frac{1}{2}} 2 F(s \mid \delta) d s\right)\right) & \\
& \times g_{d_{1}}(z, N) d z-\delta .
\end{aligned}
$$

Where, $x=\delta, t=N$, and $S=\Re^{+} \cup 0$. Therefore the only condition that we have to check is that $f(x, t)$ has increasing marginal returns, so that $\frac{\partial f}{\partial t}$ is increasing in $t$.

To verify this condition, we compute the cross derivative $\frac{\partial^{2} f}{\partial N \partial \delta}$. First, from differentiating with respect to $\delta$, we get

$$
\frac{\partial f}{\partial \delta}=-\frac{\beta}{1+\beta} \int_{0}^{\frac{1}{2}}\left(\int_{0}^{\frac{1}{2}} 2 s^{2} \frac{\partial f(s \mid \delta)}{\partial \delta} d s+\int_{\frac{1}{2}-z}^{\frac{1}{2}} 2\left(\frac{\partial F(s \mid \delta)}{\partial \delta}\right) d s\right) g_{d_{1}}(z, N) d z-1 .
$$

Integrating by parts $\frac{\partial f}{\partial \delta}$ and differentiating with respect to $N$ we get

$$
\frac{\partial^{2} f}{\partial N \partial \delta}=\frac{\beta}{1+\beta} \int_{0}^{\frac{1}{2}} 2\left(\frac{\partial F\left(\frac{1}{2}-z \mid \delta\right)}{\partial \delta}\right)\left(\frac{\partial G_{d_{1}}(z, N)}{\partial N}\right) d z
$$

Since $\frac{\partial F\left(\frac{1}{2}-z \mid \delta\right)}{\partial \delta}>0$ and $\frac{\partial G_{d_{1}}(z, N)}{\partial N}>0$ we get that the whole expression is positive, and $f(\delta, N)$ has increasing marginal returns. Therefore, applying Theorem ??, we conclude that the optimal design specification level $\delta^{E}$ is increasing in the number of firms $N$.

We use the same argument for $\beta$. Then, we compute the cross derivative,

$$
\frac{\partial^{2} f}{\partial \beta \partial \delta}=-\frac{1}{(1+\beta)^{2}} \int_{0}^{\frac{1}{2}}\left(\int_{0}^{\frac{1}{2}} 2 s^{2} \frac{\partial f(s \mid \delta)}{\partial \delta} d s+\int_{\frac{1}{2}-z}^{\frac{1}{2}} 2\left(\frac{\partial F(s \mid \delta)}{\partial \delta}\right) d s\right) g_{d_{1}}(z, N) d z
$$


This expression is positive, since by lemma ?? we know that $E_{d_{1}}\left\{S\left(d_{1}, \delta\right)\right\}$ is increasing in $\delta$, and this implies that

$$
\int_{0}^{\frac{1}{2}}\left(\int_{0}^{\frac{1}{2}} 2 s^{2} \frac{\partial f(s \mid \delta)}{\partial \delta} d s+\int_{\frac{1}{2}-z}^{\frac{1}{2}} 2\left(\frac{\partial F(s \mid \delta)}{\partial \delta}\right) d s\right) g_{d_{1}}(z, N) d z
$$

is negative. Then, applying theorem ??, we conclude that the optimal design specification level $\delta^{E}$ is increasing in the technological parameter $\beta$.

Proof of lemma ??: The bargaining problem between the winning firm and the sponsor is

$$
\max _{d^{C}, p_{F}}\left(-\left(d^{C}-d^{*}\right)^{2}-p_{F}+\left(\widehat{d}-d^{*}\right)^{2}+p_{p}\right)^{\alpha}\left(p_{F}-\beta\left(d^{C}-d_{w}\right)^{2}-p_{p}+\beta\left(\widehat{d}-d_{w}\right)^{2}\right)^{1-\alpha} .
$$

From totally differentiating with respect to $d^{C}$ and $p_{F}$ we get the two first order conditions. After simplifying we get

$$
-\left(d^{C}-d^{*}\right)-\beta\left(d^{C}-d_{w}\right)=0
$$

and

$$
(1-\alpha)\left(-\left(d^{C}-d^{*}\right)^{2}-p_{F}+\left(\widehat{d}-d^{*}\right)^{2}+p_{p}\right)=\alpha\left(p_{F}-\beta\left(d^{C}-d_{w}\right)^{2}-p_{p}+\beta\left(\widehat{d}-d_{w}\right)^{2}\right) .
$$

The solution of this system is

$$
\begin{aligned}
d^{C}= & \frac{\beta d_{w}+d^{*}}{1+\beta} \\
p_{F}= & p_{p}+\beta\left(d^{C}-d_{w}\right)^{2}-\beta\left(\widehat{d}-d_{w}\right)^{2} \\
& +\alpha\left(-\left(d^{C}-d^{*}\right)^{2}+\left(\widehat{d}-d^{*}\right)^{2}-\beta\left(d^{C}-d_{w}\right)^{2}+\beta\left(\widehat{d}-d_{w}\right)^{2}\right) .
\end{aligned}
$$

which concludes the proof.

Proof of lemma ??: First, we recall two previous results that we will use for the proof. By Lemma ?? we know that the negotiation is efficient and that given $\delta$ and the winning firm, the competitive mechanism produces the same surplus as in the efficient solution. By Lemma ?? we know that given $\delta>0$ the closest firm is the firm that produces the largest expected surplus.

Second we are going to normalize the bids in the auction. Assume that the bids are

$$
b_{i}=C_{i}(\widehat{d})-E_{d^{*}}\left\{\alpha\left(\pi_{S}+\pi_{F}-\rho_{S}-\rho_{F}\right) \mid \delta\right\}+\pi_{i} .
$$


With this normalization, we can see that $\pi_{i}$ is the expected profit of the firm $i$ when it presents the bid $b_{i}$. Using this normalization, when the sponsor grants the project to firm $i$ his expected surplus is

$$
U^{S}=S\left(d_{i}, \delta\right)-\pi_{i}-\delta
$$

Suppose that the firm $d_{j} \neq d_{1}$ is winning the project. Since, by individual rationality $\pi_{j} \geq 0$, the sponsor surplus must be lower than or equal to $S\left(d_{j}, \delta\right)-\delta$. But, in this case the closest firm $d_{I}$ can offer a better bid, with a profit $\pi_{1}=S\left(d_{1}, \delta\right)-S\left(d_{j}, \delta\right)-\epsilon$, with $\epsilon>0$. The sponsor obtains a higher surplus with this offer $\left(S\left(d_{j}, \delta\right)-\delta+\epsilon\right)$ and the closest firm obtains positive profits. Therefore, the winning firm must be the closest firm to the initial design $d_{w}=d_{1}$.

Using the same argument, we conclude that the procurement price must be

$$
b_{1}=C_{1}(\widehat{d})-E_{d^{*}}\left\{\alpha\left(\pi_{S}+\pi_{F}-\rho_{S}-\rho_{F}\right) \mid \delta\right\}+S\left(d_{1}, \delta\right)-S\left(d_{2}, \delta\right)
$$

It is easy to check that the closest firm can not increase this offer. This is because the second closest firm could get the project with a bid equal to $b_{2}=C_{2}(\widehat{d})-E_{d^{*}}\left\{\alpha\left(\pi_{S}+\pi_{F}-\rho_{S}-\rho_{F}\right) \mid \delta\right\}$.

Proof of Proposition ??: By Lemma 3 we know the expected profit of the winning firm is the difference between the expected surplus with its location and the expected surplus with the location of the second closest firm to the initial design.

$$
\begin{aligned}
\Pi(\delta) & =E_{d_{1}}\left\{S\left(d_{1}, \delta\right)\right\}-E_{d_{2}}\left\{S\left(d_{2}, \delta\right)\right\} \\
& =\int_{0}^{\frac{1}{2}}-\frac{\beta}{1+\beta}\left(z^{2}-2 z+\int_{\frac{1}{2}-z}^{\frac{1}{2}} 2 F(s \mid \delta) d s\right)\left(g_{d_{1}}(z, N)-g_{d_{2}}(z, N)\right) d z
\end{aligned}
$$

We integrate by parts this expression to get

$$
\begin{aligned}
& {\left[-\frac{\beta}{1+\beta}\left(z^{2}-2 z+\int_{\frac{1}{2}-z}^{\frac{1}{2}} 2 F(s \mid \delta) d s\right)\left(G_{d_{1}}(z, N)-G_{d_{2}}(z, N)\right)\right]_{0}^{\frac{1}{2}}} \\
& +\int_{0}^{\frac{1}{2}}\left(\frac{\beta}{1+\beta}\left(2 z-2+2 F\left(\frac{1}{2}-z \mid \delta\right)\right)\left(G_{d_{1}}(z, N)-G_{d_{2}}(z, N)\right) d z\right.
\end{aligned}
$$

Differentiating with respect to $\delta$ we get

$$
\frac{\partial \Pi(\delta)}{\partial \delta}=\int_{0}^{\frac{1}{2}}\left(\frac{2 \beta}{1+\beta} \frac{\partial F\left(\frac{1}{2}-z \mid \delta\right)}{\partial \delta}\right)\left(G_{d_{1}}(z, N)-G_{d_{2}}(z, N)\right) d z
$$


This expression is positive, since by Assumption $3 \frac{\partial F\left(\frac{1}{2}-z \mid \delta\right)}{\partial \delta}>0$, and $G_{d_{1}}(z, N)>G_{d_{2}}(z, N)$ for all $z \in\left(0, \frac{1}{2}\right)$.

Proof of Proposition ??: We follow the same argument that we have used in the proof of Proposition ??.

Proof of Proposition ??: The competitive problem is

$$
\delta^{C} \in \underset{\delta}{\operatorname{argmax}} E_{d_{2}}\left\{S\left(d_{2}, \delta\right)-\delta\right\}
$$

This problem is equivalent to

$$
\delta^{C} \in \underset{\delta}{\operatorname{argmax}} E_{d_{1}, d_{2}}\left\{S\left(d_{1}, \delta\right)-\Pi(\delta)-\delta\right\}
$$

Where $\Pi(\delta)=E_{d_{1}}\left\{S\left(d_{1}, \delta\right)\right\}-E_{d_{2}}\left\{S\left(d_{2}, \delta\right)\right\}$ is the expected profit of the winning firm. By Lemma ?? we know that $\frac{\partial \Pi(\delta)}{\partial \delta}>0$. In order to show the result we will show that $\delta^{C}>\delta^{E}$ and $\delta^{C}=\delta^{E}$ are not possible.

- Case 1: $\delta^{C}>\delta^{E}$. This is not possible, since in this case $\delta^{E}$ provides more surplus to the sponsor than $\delta^{C}$.

$$
E_{d_{2}, d_{1}}\left\{S\left(d_{1}, \delta^{E}\right)-\Pi\left(\delta^{E}\right)-\delta^{E}\right\}>E_{d_{2}, d_{1}}\left\{S\left(d_{1}, \delta^{C}\right)-\Pi\left(\delta^{C}\right)-\delta^{C}\right\}
$$

This inequality follows from $\delta^{E} \in \operatorname{argmax}\left\{E_{d_{1}, d^{*}}\left\{S\left(d_{1}, \delta\right)-\delta\right\}\right\}$ and $\Pi\left(\delta^{E}\right)<\Pi\left(\delta^{C}\right)$.

- Case 2: $\delta^{C}=\delta^{E}$. It is not possible since $\delta^{E} \in \operatorname{argmax}\left\{E_{d_{1}, d^{*}}\left\{S\left(d_{1}, \delta\right)-\delta\right\}\right\}$ and $\frac{\partial \Pi(\delta)}{\partial \delta}>0$ implies than $\delta^{C}=\delta^{E}$ cannot satisfies the first order condition of the problem.

Proof of proposition ??: The expected cost overruns are

$$
C_{C O}=E_{d_{1}, d^{*}}\left\{C_{1}\left(d^{C}\right)-C_{1}(\widehat{d})+\alpha\left(\pi_{S}+\pi_{F}-\rho_{S}-\rho_{F}\right) \mid \delta\right\}
$$

Since $C_{1}(\widehat{d})$ does not depend on $\delta$, in order to show that the cost overruns are decreasing in $\delta$, we only need to show that $E_{d_{1}, d^{*}}\left\{C_{1}\left(d^{C}\right) \mid \delta\right\}$ and $E_{d_{1}, d^{*}}\left\{\alpha\left(\pi_{S}+\pi_{F}-\rho_{S}-\rho_{F}\right) \mid \delta\right\}$ are decreasing in $\delta$. 
By plugging the expression of the optimal design $d^{C}=\frac{\beta d_{1}+d^{*}}{(1+\beta}$ into $E_{d_{1}, d^{*}}\left\{C_{1}\left(d^{C}\right) \mid \delta\right\}$, and then factorizing, we get

$$
E_{d_{1}, d^{*}}\left\{C_{1}\left(d^{C}\right) \mid \delta\right\}=E_{d_{1}, d^{*}}\left\{C+\beta\left(d^{C}-d_{1}\right)^{2} \mid \delta\right\}=E_{d_{1}, d^{*}}\left\{C+\frac{\beta}{(1+\beta)^{2}}\left(d^{*}-d_{1}\right)^{2} \mid \delta\right\} .
$$

Therefore we need to show that $E_{d_{1}, d^{*}}\left\{\left(d^{*}-d_{1}\right)^{2} \mid \delta\right\}$ is decreasing on $\delta$. But this was proved in the proof of Lemma ??.

We denote by $R(\delta)$ the rent of the awarded firm in the renegotiation of the design.

$$
\begin{aligned}
& R(\delta)=E_{d_{1}, d^{*}}\left\{\alpha\left(\pi_{S}+\pi_{F}-\rho_{S}-\rho_{F}\right) \mid \delta\right\} \\
& R(\delta)=E_{d_{1}, d^{*}}\left\{\alpha\left(-\left(d^{C}-d^{*}\right)^{2}+\left(\widehat{d}-d^{*}\right)^{2}-\beta\left(d^{C}-d_{1}\right)^{2}+\beta\left(\widehat{d}-d_{1}\right)^{2}\right) \mid \delta\right\}
\end{aligned}
$$

Rearranging terms and using straightforward calculations we get

$$
R(\delta)=E_{d_{1}, d^{*}}\left\{\frac{-\alpha \beta}{(1+\beta)}\left(d^{*}-d_{1}\right)^{2} \mid \delta\right\}+E_{d_{1}}\left\{\alpha \beta\left(\widehat{d}-d_{1}\right)^{2}\right\}+E_{d^{*}}\left\{\alpha\left(\widehat{d}-d^{*}\right)^{2} \mid \delta\right\}
$$

We can use the computation of the proof of lemma ?? to simplify again the equation as

$$
\begin{aligned}
R(\delta)= & E_{d_{1}}\left\{\frac{-\beta \alpha}{(1+\beta)}\left(d_{1}^{2}+\int_{0}^{\frac{1}{2}} 2 s^{2} f(s \mid \delta) d s-2 d_{1}+\int_{\frac{1}{2}-d_{1}}^{\frac{1}{2}} 2 F(s \mid \delta) d s\right)\right\} \\
& +E_{d_{1}}\left\{\alpha \beta\left(\widehat{d}-d_{1}\right)^{2}\right\}+\alpha \int_{0}^{\frac{1}{2}} 2 s^{2} f(s \mid \delta) d s .
\end{aligned}
$$

Rearranging terms we get

$$
\begin{aligned}
R(\delta)= & \frac{\alpha}{1+\beta} \int_{0}^{\frac{1}{2}} 2 s^{2} f(s \mid \delta) d s-E_{d_{1}}\left\{\frac{\beta \alpha}{(1+\beta)}\left(\int_{\frac{1}{2}-d_{1}}^{\frac{1}{2}} 2 F(s \mid \delta) d s\right)\right\} \\
& E_{d_{1}}\left\{\alpha \beta\left(\widehat{d}-d_{1}\right)^{2}\right\}-E_{d_{1}}\left\{\frac{\beta \alpha}{(1+\beta)}\left(d_{1}^{2}-2 d_{1}\right)\right\} .
\end{aligned}
$$

The whole expression is decreasing in $\delta$. The first term is decreasing in $\delta$, since $\int_{0}^{\frac{1}{2}} 2 s^{2} f(s \mid \delta) d s$ is the variance of $d^{*}$. The second term is decreasing in $\delta$, since by assumption $3 F(d \mid \delta)$ is increasing in $\delta, \forall d \in\left[\widehat{d}, \widehat{d}+\frac{1}{2}\right]$. Finally, the third and fourth terms do not depend on $\delta$. The whole argument implies that $R(\delta)$ is decreasing on $\delta$ and this concludes the proof.

Proof of corollary ??: Immediate from propositions ?? and ??.

Proof of proposition ??: By the same argument of the proof of Proposition ??, given that $\delta^{E} \in \operatorname{argmax}\left\{E_{d_{1}, d^{*}}\left\{S\left(d_{1}, \delta\right)-\delta\right\}\right\}$ and $\delta^{I I} \in \operatorname{argmax}\left\{E_{d_{1}, d^{*}}\left\{S\left(d_{1}, \delta\right)-\delta-R(\delta)\right\}\right\}$, in order to 
prove $\delta^{E}<\delta^{I I}$, we only need to show that $R(\delta)$ is decreasing in $\delta$. But this was proven in Proposition ??.

Proof of corollary ??: Notice that

$$
E_{d_{2}, d^{*}}\left\{S\left(d_{2}, \delta^{C}\right)-\delta^{C}\right\}>E_{d_{2}, d^{*}}\left\{S\left(d_{2}, \delta^{I I}\right)-\delta^{I I}\right\}
$$

is immediate because $\delta^{C} \in \operatorname{argmax}\left\{E_{d_{2}, d^{*}}\left\{S\left(d_{2}, \delta\right)-\delta\right\}\right\}$, and $\delta^{C} \neq \delta^{I I}\left(\delta^{E} \leq \delta^{I I}\right.$ and $\left.\delta^{E}>\delta^{C}\right)$. 


\section{B REFERENCES}

\section{REFERENCES}

[1] Arvan, L. and A. Leite (1990) "Cost overruns in long-term project", International Journal of Industrial Organization, 8(3), 443-67.

[2] Augustine, N (1986). Augustine’ Laws. Viking Penguin Inc. New York, USA.

[3] Bajari, P. and Tadelis, S. (2001) "Incentives versus transaction cost. A theory of procurement contracts", Rand Journal of Economics, 32, 387-407.

[4] Bergemann, D. and Pesendorfer, M. (2003) "Information Structures in Optimal Auctions", mimeo, London School of Economics.

[5] Che, Y.-K. (1993) "Design competition through multidimensional auction", Rand Journal of Economics, 24, 668-680.

[6] Chen, Y. and Smith, R. (2001) "Design competition through multidimensional auction", Annals of Economics and Finance, 2, 401-414.

[7] Edlin, A. and C. Shannon (1998) "Strict monotonicity in comparative statics", Journal of Economic Theory, 81, 201-219.

[8] Ganuza, J.-J. (1996) "Strategic behavior in procurement contracts", Ph.D. Dissertation, Universidad Carlos III de Madrid.

[9] Ganuza, J.-J. (1997) "Los sobrecostes en las obras públicas. Un análisis económico del caso español", Economía Industrial, 318, 111-122.

[10] Ganuza, J.-J. (2003) "Competition and Cost Overruns. Optimal Misspecification of Procurement Contracts", Universitat Pompeu Fabra, Department of Economics and Business, Working Paper no. 471. 
[11] Ganuza, J.-J. (2004) "Ignorance promotes competition. An auction model of endogenous private valuations", forthcoming in Rand Journal of Economics.

[12] Ganuza, J.-J. and Penalva (2004) "Optimal Information Transmition in Private Value Auctions", mimeo, Universitat Pompeu Fabra.

[13] Ganuza, Juan-José and Lambros Pechlivanos (2000), "Heterogeneity-Promoting Optimal Procurement", Economics Letters, 67(1), 105-112.

[14] Gaspar, V. and A. Leite (1989) "Selection bias induced cost overruns", International Journal of Industrial Organization, 8(3), 443-467.

[15] Jofre-Bonet, M. and M. Pesendorfer (2003) "Estimation of a Dynamic Auction Game", Econometrica, 71(5), 1443-1489.

[16] Laffont, J. and J. Tirole (1993) A theory of incentives in procurement and regulation, M.I.T. Publishing Press, Cambridge Massachusetts, USA.

[17] Lewis, T. (1986) "Reputation and contractual performance in long-term projects", Rand Journal of Economics, 17, 141-157.

[18] Lewis, T. and D. E. M. Sappington (1994) "Supplying information to facilitate price discrimination", International Economic Review, 35, 309-327.

[19] Milgrom, P. and C. Shannon (1994) "Monotone comparative statics", Econometrica, 62, $157-180$.

[20] Peck, M.S. and F.M. Scherer (1962). The Weapons Acquisition Process: An Economic Analysis. The Harvard University Press, Boston, MA, USA. 


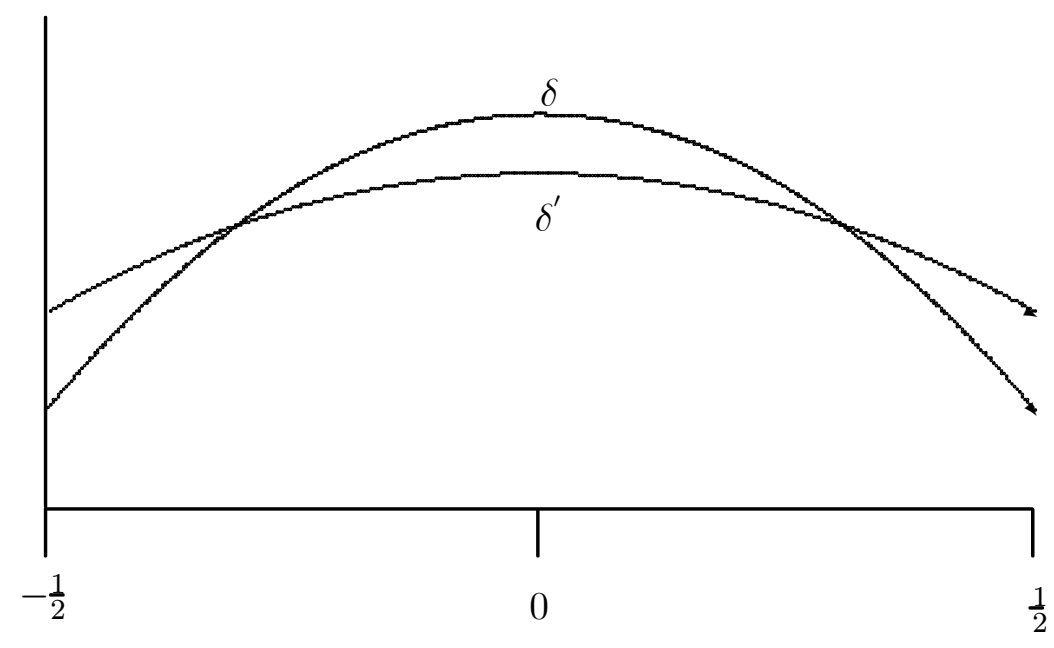

Figure 1: Two arbitrary density functions of $e$ where $\delta>\delta^{\prime}$. 